DOI: 10.30680/ECO0131-7652-2018-5-28-44

\section{Национальное и религиозное разнообразие регионов Сибири}

А.Н. БУФЕТОВА, кандидат экономических наук, Институт экономики и организации промышленного производства СО РАН, Новосибирский национальный исследовательский государственный университет. E-mail: bufetova@gmail.com

Е.А. КОЛОМАК, доктор экономических наук, Институт экономики

и организации промышленного производства СО РАН, Новосибирский национальный исследовательский государственный университет. E-mail: ekolomak@academ.org

А.А. ХРЖАНОВСКАЯ, Институт экономики и организации промышленного производства СО РАН, Новосибирск. E-mail: AlinKhrzh57@mail.ru

В работе тестируется гипотеза о более высокой этнической и религиозной гетерогенности населения территории Сибири в сравнении с общероссийскими данными. На основе переписей населения 2002 и 2010 гг. и данных по вероисповеданию за 2012 и 2015 гг. получены количественные оценки национального и религиозного разнообразия для России в целом и для регионов Сибири. В анализе использовались индексы неоднородности и поляризации. Результать не подтвердили предположение о том, что Сибирь отличается высоким национальным разнообразием, кроме того, в регионе наблюдается более быстрое сокращение этнической неоднородности по сравнению с Россией. Гетерогенность религиозного состава населения Сибири несколько выше среднего уровня по стране, но тенденция к большей однородности выражена сильнее.

Ключевые слова: национальная структура, религия, население, разнообразие, Россия, Сибирь

В современной научной повестке все больше внимания уделяется роли факторов неэкономической природы в формировании стимулов и поведения экономических агентов, что, в свою очередь, влияет на динамику развития общества в целом. Как правило, эта связь устанавливается через формальные и неформальные институты. Нормы и правила вырастают из истории, традиций и культуры, создавая разнообразие в институциональной среде, влияя на качество регионального и муниципального управления

Воздействие национальных и религиозных установок на институты и экономическое развитие прослеживается через социальный капитал, определяющий доверие между людьми, через элементы деловой этики и особенности накопления человеческого капитала [Becker, Woessmann, 2009; Tabelini, 2008;
LaPorta et al., 1997; Grosfeld et al., 2013; Menyashev, Polishchuk, 2011; Ягольницер, 2014].

Если в отношении культуры и религии в научной литературе в основном разделяется точка зрения, что эти неформальные институты, формируя общие нормы и ценности, способствуют интеграции общества, выполняют функции координации и играют положительную роль в социальных и экономических процессах, то этническое и религиозное разнообразие в экономической теории рассматривается и как ресурс развития, и как источник серьёзных конфликтов, которые могут отвлекать ограниченные средства и сдерживать рост. При этом положительные эффекты неоднородности обсуждаются, как правило, в контексте долгосрочной эволюции [Даймонд, 2016], противоречия же, вытекающие из неоднородности, фигурируют в текущей повестке, поэтому сопоставление выгод и издержек является сложной задачей. Но в любом случае при разработке политики и принятии управленческих решений должны учитываться особенности институциональной структуры общества, возможности противоречий из-за культурных различий и потенциальные выгоды, которые несут разнообразие накопленных навыков и диверсификация общества.

В предыдущей статье А.Н. Буфетовой и Е.А. Коломак были представлены оценки национального разнообразия и поляризации в современной России [Буфетова, Коломак, 2017]. В предлагаемой работе используются результаты авторов, полученные ранее, а также приводятся данные сравнительного анализа этнического и религиозного разнообразия сибирской территории.

Для Сибири как региона нового освоения всегда была характерна высокая миграционная составляющая демографических процессов. Естественно предположить, что этническая и религиозная неоднородность в связи с этим должна быть в Сибири выше, чем в России в целом, так как добровольное и принудительное переселение в регион охватывало разные этнические группы и представителей разных конфессий. Последствия шоков политических и экономических реформ, активная внутренняя и внешняя миграция, изменение роли религии в обществе и кардинальное преобразование институтов также существенно повлияли на этническое и религиозное разнообразие этого региона. 
В связи с этим наше предположение состоит в том, что Сибирь является территорией, где уровень этнического и культурного разнообразия существенно выше среднего в России. Неоднородность населения создаёт основу для различий в предпочтениях жителей и в их оценках качества общественных благ, и это должно учитываться в процессах управления развитием территорией, в выборе механизмов и инструментов реализации политических решений.

Сибирь в данной работе рассматривается в границах макрорегиона, включающего, наряду с 12 субъектами Сибирского федерального округа, Тюменскую область, Ямало-Ненецкий и Ханты-Мансийский автономные округа.

\section{Как измерить «сибирский интернационал»?}

Источником информации о национальном составе населения субъектов Российской Федерации выступали данные всероссийских переписей населения 2002 и 2010 гг. ${ }^{1}$ Для количественной оценки уровня неоднородности разработаны две группы индексов: первая объединяет показатели разнообразия и ассоциируется с положительными эффектами; вторая включает показатели поляризации и связывается с рисками конфликта. В данной работе оценивался один показатель поляризации и две оценки разнообразия - индекс неоднородности и энтропия. Свойства этих характеристик, их преимущества и недостатки обсуждаются в работе А. Буфетовой и Е. Коломак (2017).

Индекс неоднородности рассчитывается по формуле: $\mathrm{F}=1-\sum_{\mathrm{i}=1}^{\mathrm{N}}\left(\mathrm{s}_{\mathrm{i}}\right)^{2}$, где $\mathrm{S}_{\mathrm{i}}$ - доля населения $\mathrm{i}$-й этнической группы в общей численности населения, $\mathrm{N}$ - число таких групп. Индекс принимает значения от 0 до $1-1 / \mathrm{N}$. Показатель энтропии определяется по формуле: $\mathrm{E}=\sum_{\mathrm{i}=1}^{\mathrm{N}}\left(\mathrm{s}_{\mathrm{i}}\right) \cdot \ln \left(\frac{1}{\mathrm{~s}_{\mathrm{i}}}\right)$. Максимальное значение индекса зависит от числа групп и равно $\ln N$. Поэтому для сопоставимости показатель нормировался к максимальному значению для каждого региона.

${ }^{1}$ В указанных источниках данные по Тюменской области приведены в целом, с включением автономных округов, и по каждому округу отдельно. Поэтому для Тюменской области без округов была получена оценка путем вычитания численности населения соответствуюшей национальности в автономных округах из общего показателя
Индекс поляризации используется для оценки возможности конфликтов и характеризует распределение населения между группами. В литературе разработано несколько подходов к оценке поляризации, в данной работе используется индекс, предложенный Монталво и Рейнал-Кверол (Montalvo, Reynal-Querol, 2002), который является мерой отличия фактического распределения населения по этническим группам от бимодального:

$$
\mathrm{DP}=1-\sum_{\mathrm{i}=1}^{\mathrm{N}}\left(\frac{0,5-\mathrm{s}_{\mathrm{i}}}{0,5}\right) \mathrm{s}_{\mathrm{i}}
$$

\section{Чей интернационал разнообразнее?}

Во всех сибирских регионах, кроме Республики Тыва, доминирующим этническим большинством является русское население. Его доля в 2010 г. колебалась от 56,6\% в Республике Алтай до 93,9\% в Алтайском крае. При этом доля русских возросла в 2010 г. по сравнению с 2002 г. в большей части регионов; исключение составляют республики Алтай, Бурятия и Тыва, где его доля сокращается (табл. 1).

\section{Таблица 1. Показатели этнического разнообразия в регионах} в 2002 r., 2010 r., \%

\begin{tabular}{|c|c|c|c|c|c|c|}
\hline \multirow[t]{2}{*}{ Показатель } & \multicolumn{2}{|c|}{$\begin{array}{c}\text { Индекс } \\
\text { неоднородности }\end{array}$} & \multicolumn{2}{|c|}{$\begin{array}{c}\text { Показатель } \\
\text { энтропии }\end{array}$} & \multicolumn{2}{|c|}{$\begin{array}{c}\text { Индекс } \\
\text { поляризации }\end{array}$} \\
\hline & Сибирь & Россия & Сибирь & Россия & Сибирь & Россия \\
\hline $\begin{array}{l}\text { Доля регионов, где показа- } \\
\text { тель разнообразия меньше } \\
\text { российского: }\end{array}$ & & & & & & \\
\hline 2002 г. & 67 & 56 & 80 & 67 & 60 & 55 \\
\hline 2010 г. & 73 & 59 & 80 & 69 & 60 & 55 \\
\hline $\begin{array}{l}\text { Доля регионов с растущим } \\
\text { показателем разнообразия }\end{array}$ & 6,7 & 18 & 6,7 & 21 & 20 & 26,5 \\
\hline $\begin{array}{l}\text { Максимальное увеличение } \\
\text { показателя разнообразия }\end{array}$ & $\begin{array}{c}2,6 \\
\text { (Республи- } \\
\text { ка Бурятия) }\end{array}$ & 11,3 & $\begin{array}{c}2,6 \\
\text { (Новосибир- } \\
\text { ская обл.) } \\
\end{array}$ & 13.3 & $\begin{array}{c}\text { 4,4 } \\
\text { (Республи- } \\
\text { ка Алтай) }\end{array}$ & 10,2 \\
\hline $\begin{array}{l}\text { Максимальное сокращение } \\
\text { показателя разнообразия }\end{array}$ & $\begin{array}{c}23 \\
\text { (Алтайский } \\
\text { край) }\end{array}$ & 69 & $\begin{array}{c}16,5 \\
\text { (Алтайский } \\
\text { край) }\end{array}$ & 57,5 & $\begin{array}{c}21,5 \\
\text { (Алтайский } \\
\text { край) }\end{array}$ & 68 \\
\hline
\end{tabular}

В Республике Тыва доминирующей национальностью были тувинцы, доля которых составляла $77 \%$ в 2002 г. и $82 \%-$ 
в 2010 г., а доля доминирующего этнического меньшинства русского населения - сокращалась с 20 до 16,3\%.

Все показатели разнообразия в большинстве сибирских регионов - ниже, чем соответствующие индексы, рассчитанные для России в целом. Кроме того, в Сибири меньше доля регионов, где индексы разнообразия выросли с 2002 г. по 2010 г. (см. табл. 1). Индекс неоднородности увеличивается только в одном регионе (Республика Бурятия), показатель энтропии - тоже в одном (Новосибирская область), индекс поляризации - в трех регионах республиках Алтай и Бурятия и Забайкальском крае (рис. 1). В остальных регионах показатели разнообразия сокращаются. При этом по сравнению с Россией сибирские регионы демонстрируют более слабую динамику показателей разнообразия: максимальное увеличение и сокращение показателей здесь гораздо меньше, чем по всей стране.

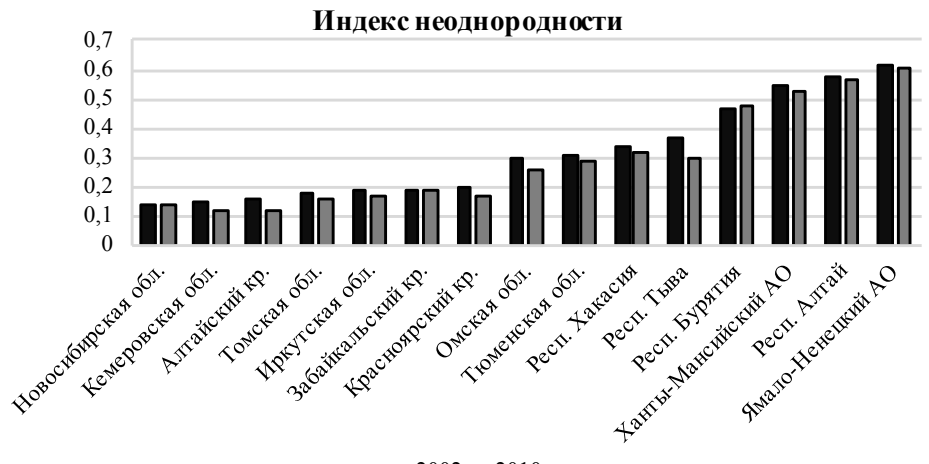

Q2002 口2010

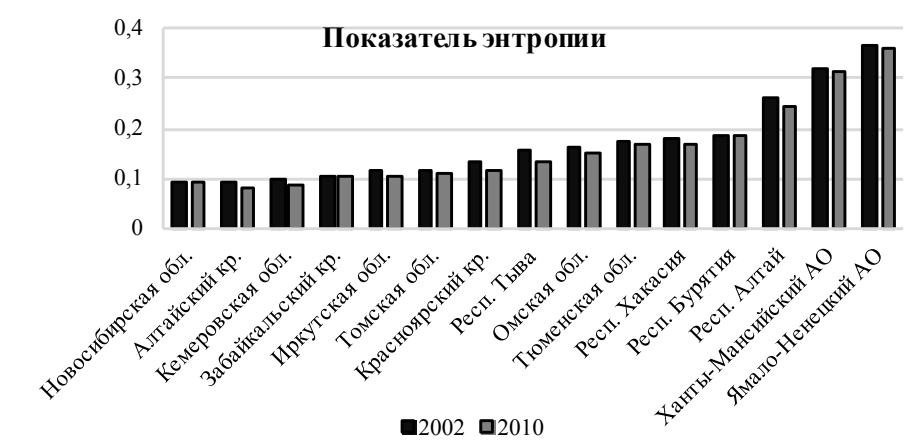

Индекс поляризации
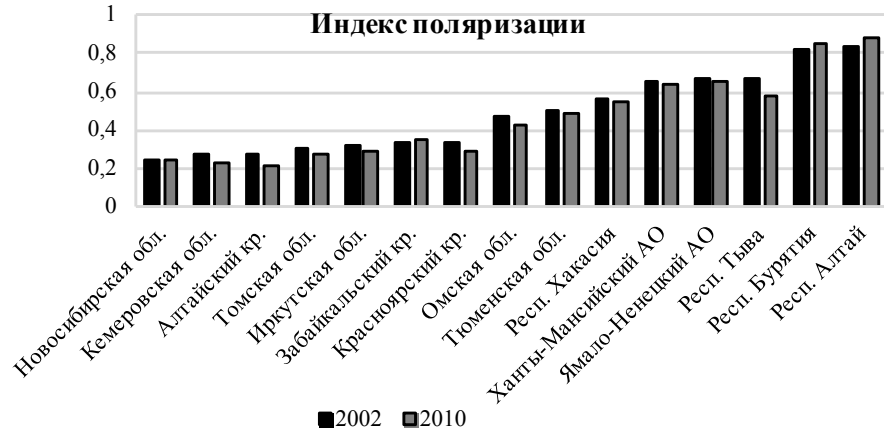

Рис. 1. Динамика показателей разнообразия в регионах Сибири в 2002 г. и 2010 г.

В 2002 г. в пяти сибирских регионах индекс национальной неоднородности был выше российского уровня, в 2010 г. число таких регионов сократилось до четырех (рис. 2). Во всех случаях это национальные республики и автономные округа. На первом месте - Ямало-Ненецкий автономный округ, затем идут Республика Алтай и Ханты-Мансийский автономный округ, на четвертом месте - Республика Бурятия. В 2002 г. индекс неоднородности превышал российский уровень в Республике Тыва, но к 2010 г. степень неоднородности в этом регионе сократилась: возросла доля доминирующего этнического большинства - тувинцев.

Показатель энтропии национальной структуры превышает российский уровень только в трех регионах - Ямало-Ненецком и Ханты-Мансийском автономных округах и Республике Алтай (рис. 3). Республика Бурятия занимает четвертое место по величине индекса энтропии, но его значение уже ниже российского показателя. Лидерами по показателю энтропии национальной структуры в Сибири, как и в России, являются национальные образования. В тройке регионов с самыми низкими показателями, причем как по индексу неоднородности, так и по показателю энтропии, - Новосибирская область, Алтайский край и Кемеровская область. 

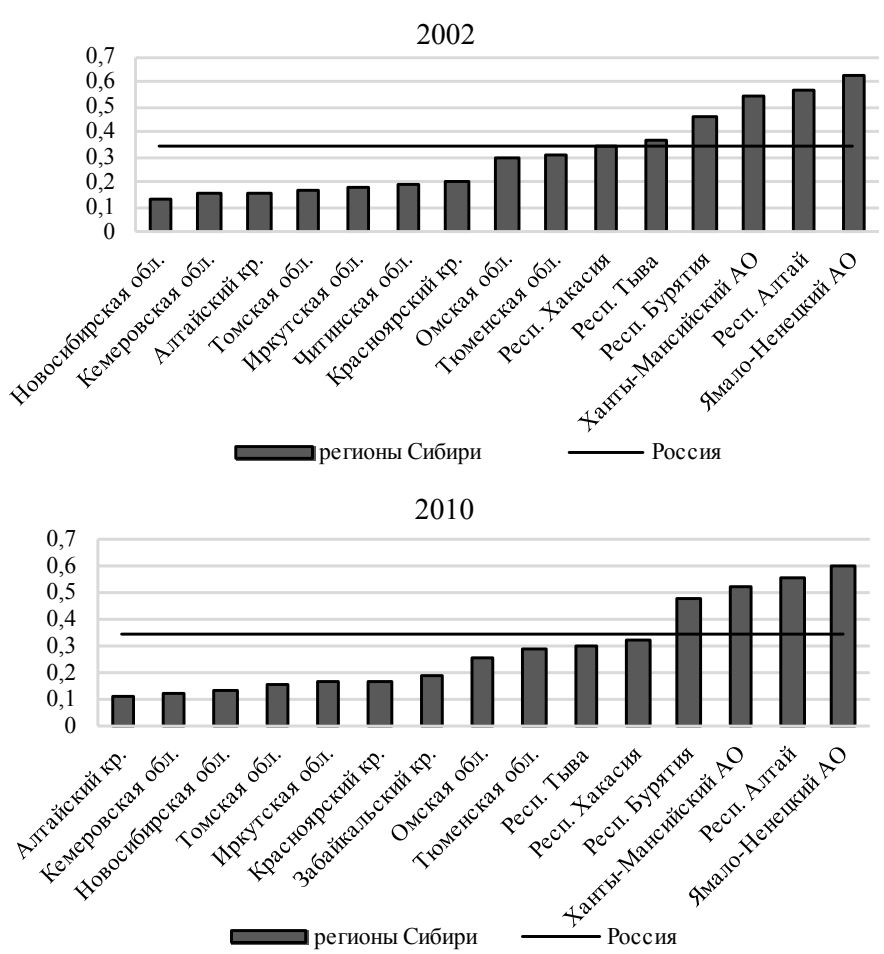

Рис 2. Индексы неоднородности в регионах Сибири и в России в 2002 г. и 2010 г.

Значение индекса поляризации превышает российский уровень в шести регионах (рис. 4). Это все те же национальные республики и автономные округа: республики Алтай, Бурятия и Тыва, Ханты-Мансийский и Ямало-Ненецкий автономные округа, Республика Хакасия. Во всех этих регионах, кроме Республики Тыва, доминирующим этническим большинством являются русские, а преобладающим этническим меньшинством - титульная нация в республиках и украинцы - в ХантыМансийском и Ямало-Ненецком АО. Однако индекс поляризации увеличивается только в двух регионах - республиках Алтай и Бурятия.
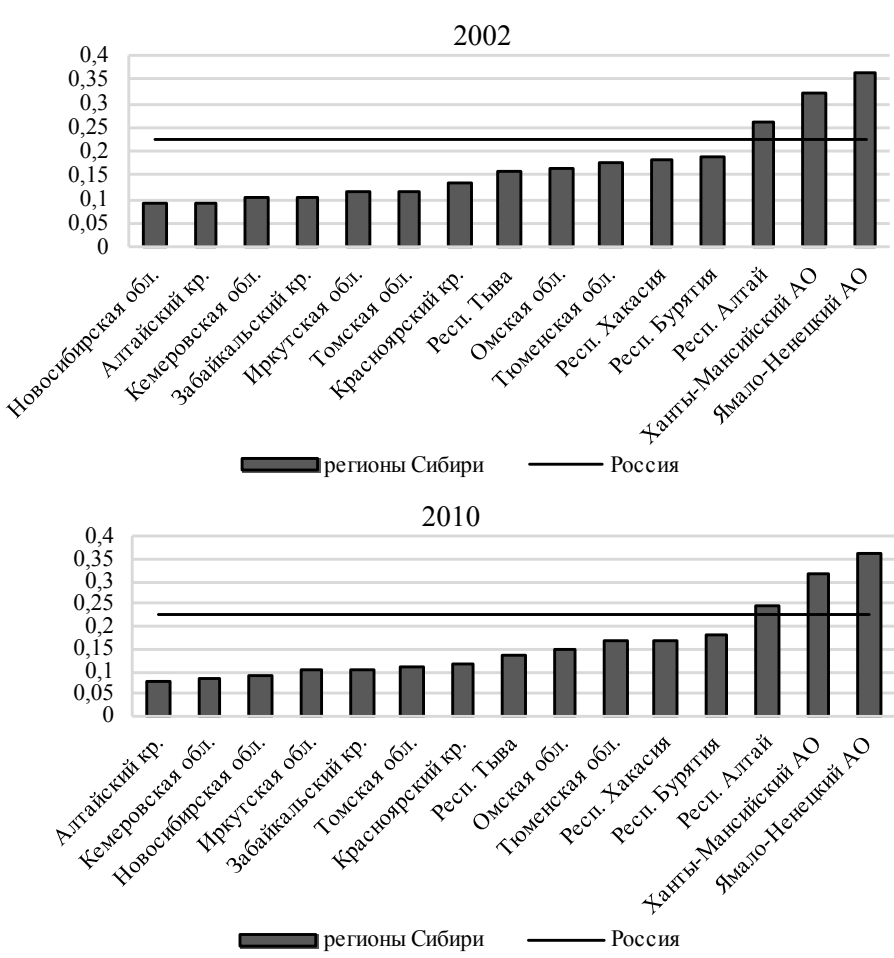

Рис. 3. Показатели энтропии в регионах Сибири и в России в 2002 г. и 2010 г.

Особенности распределения регионов Сибири по национальным группам показаны на рисунке 5. На горизонтальной оси зафиксирована доля этнического большинства, а на вертикальной - доля доминирующего этнического меньшинства, то есть второй по величине этнической группы в регионе. Если доля этнического большинства составляет $p$, то доля доминирующего этнического меньшинства не может превышать (1-p). Поэтому все точки, обозначающие комбинации этих величин в регионах, находятся внутри треугольника с вершинами в точках $(0,0)$, $(0,5 ; 0,5)$ и $(1,0)$. Регионы, расположенные вблизи точки $(1,0)$, имеют крупное этническое большинство и потому относительно однородны. Регионы, расположенные вблизи вершины $(0,0)$, характеризуются дисперсной национальной структурой и поэтому 
очень неоднородны. В регионах, расположенных вблизи вершины $(0,5 ; 0,5)$, наблюдается поляризованное распределение населения по национальному признаку.

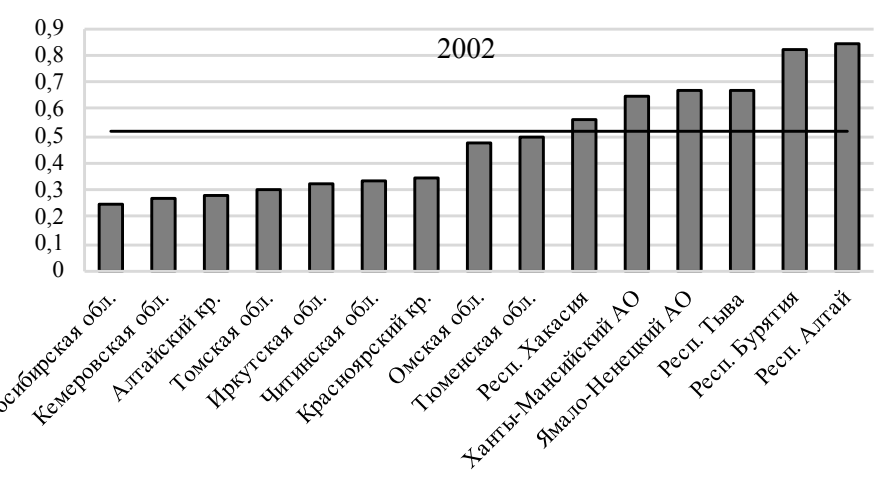

щегионы Сибири — Россия

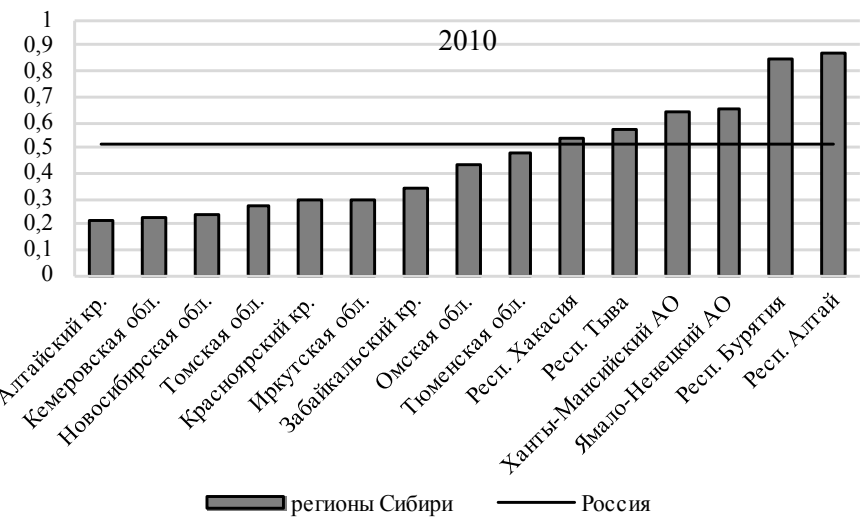

Рис. 4. Индексы поляризации в регионах Сибири и России в 2002 г. и 2010 г.

Данные рисунков показывают, что регион с наиболее поляризованной национальной структурой населения - Республика Алтай, где доля этнического большинства (русские) составляет около $57 \%$ (57,5 и 56,7\% в 2002 г. и в 2010 г. соответственно), а доля доминирующего этнического меньшинства (алтайцы) 30,7 и $33,9 \%$ в 2002 г. и 2010 г., соответственно. Так что поляризация по национальному составу в республике несколько усиливается, и на графике положение региона смещается к вершине треугольника.
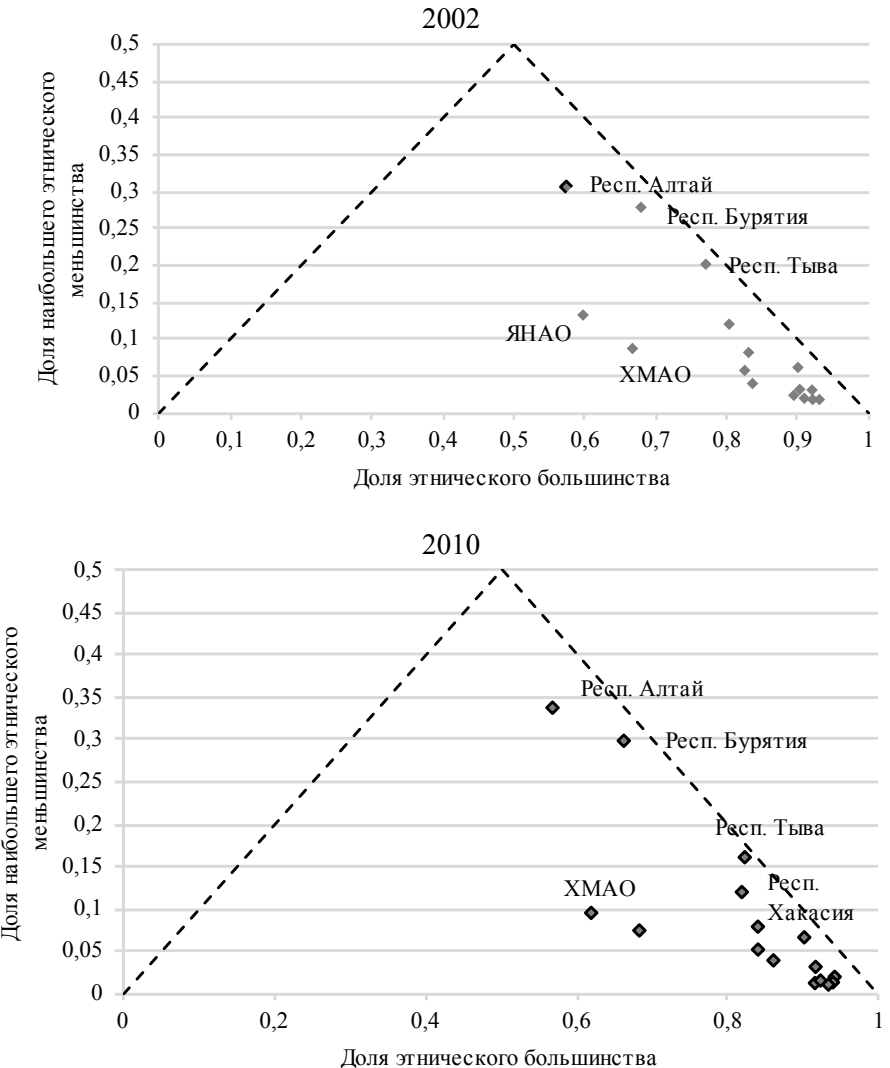

Рис. 5. Сопоставление долей этнического большинства и доминирующего этнического меньшинства в регионах Сибири в 2002 г. и 2010 г.

В Республике Бурятия этническое большинство (русские) составляет $68 \%$ в 2002 г. и $66 \%$ в 2010 г., а доминирующее этническое меньшинство (буряты) - 27,8\% в 2002 г. и $30 \%$ в 2010 г.

Тройка регионов с самым низким показателем, так же как и группа лидеров по индексу поляризации, остается в 2002 и 2010 гг. без изменения - это Новосибирская, Кемеровская области и Алтайский край. Во всех этих регионах доля этнического 
большинства составляет 92-93\%, а самая значительная доля этнического меньшинства $-1,7 \%$ в Новосибирской и Кемеровской областях и $3 \%$ - в Алтайском крае.

Основные итоги проведённого сравнения регионов Сибири и России в целом следующие:

- регионы Сибири имеют несколько меньший уровень национального разнообразия, чем страна в целом;

- общероссийская тенденция сокращения национального разнообразия в Сибири проявляется в относительно большем числе регионов;

- в сибирских регионах динамика как роста, так и сокращения национального разнообразия более слабая.

Таким образом, наше первоначальное предположение о том, что активные исторические и современные миграционные процессы привели к более разнообразному национальному составу в Сибири, не подтвердилось. Этот результат говорит о том, что структура мигрантов в сибирских регионах является более однородной по сравнению с показателями, характерными для страны в целом.

\section{Не только этничность, но и религия}

Важным институтом, влияющим на поведение населения в различных экономических и социальных сферах, является религия. Наше предположение состояло в том, что сибирские регионы должны иметь более высокий уровень культурного разнообразия, проверим его по отношению к религии.

Конфессиональный состав населения Российской Федерации, несмотря на доминирование православной религии, достаточно разнообразен. Анализ неоднородности в религиозной принадлежности проводился для 2012 и 2015 гг.2 Перечень вероисповеданий, по которым представлена статистика религиозной принадлежности, для разных лет имеет разную детализацию. Данные за 2012 г. дают более подробную структуру населения по вероисповеданию. Поэтому для обеспечения сопоставимости за основу принята группировка 2015 г., включающая следующий набор религиозных ответвлений:

Информация за 2012 г. здесь и в табл. 2-3 представлена атласом религий и национальностей России «Арена» (некоммерческая исследовательская служба «Среда»), данные за 2015 г. подготовлены Федеральным агентством по делам национальностей
- православие (включает граждан, исповедующих православие и при этом как принадлежащих к Русской православной церкви, так и не относящихся к ней, но не являющихся старообрядцами);

- ислам (исповедующие ислам, но не являющиеся ни суннитами, ни шиитами, а также исповедующие ислам шиитского направления);

- буддизм (исповедующие буддизм);

- атеизм (не верующие в Бога);

- своя вера (верующие в Бога (в высшую силу), но не конкретную религию; исповедующие протестантизм (лютеранство, баптизм, евангелизм, англиканство), а также пятидесятничество; исповедующие христианство, но не считающие себя ни православными, ни католиками, ни протестантами; исповедующие иудаизм, восточные религии и духовные практики (индуизм, кришнаизм, другие направления));

- язычество (исповедующие традиционную религию своих предков, поклоняющиеся богам и силам природы);

- прочие;

- старообрядчество (исповедующие православие, являющиеся старообрядцами (староверами));

- католицизм (исповедующие католицизм).

Характеристики соотношения долей населения по исповедуемым религиям в разрезе регионов РФ представлены таблицах 2-5.

Таблица 2. Характеристики религиозного состава регионов РФ 2012 r.

\begin{tabular}{|c|l|c|c|c|c|c|c|}
\hline Ранг & Религия & $\begin{array}{c}\text { Макси- } \\
\text { мальное } \\
\text { значение }\end{array}$ & $\begin{array}{c}\text { Мини- } \\
\text { мальное } \\
\text { значение }\end{array}$ & $\begin{array}{c}\text { Среднее } \\
\text { значение }\end{array}$ & $\begin{array}{c}\text { Стандарт- } \\
\text { ное откло- } \\
\text { нение }\end{array}$ & $\begin{array}{c}\text { Меди- } \\
\text { ана }\end{array}$ & $\begin{array}{c}\text { Коэф- } \\
\text { фициент } \\
\text { вариции }\end{array}$ \\
\hline 1 & Ислам & 0,826 & 0,000 & 0,057 & 0,133 & 0,011 & 2,345 \\
\hline 2 & Православие & 0,784 & 0,010 & 0,405 & 0,155 & 0,366 & 0,384 \\
\hline 3 & Буддизм & 0,618 & 0,000 & 0,016 & 0,084 & 0,000 & 5,068 \\
\hline 4 & Своя вера & 0,464 & 0,074 & 0,302 & 0,103 & 0,308 & 0,341 \\
\hline 5 & Атеизм & 0,347 & 0,022 & 0,132 & 0,059 & 0,130 & 0,447 \\
\hline 6 & Язычество & 0,294 & 0,000 & 0,019 & 0,040 & 0,008 & 2,140 \\
\hline 7 & Прочие & 0,192 & 0,006 & 0,064 & 0,040 & 0,058 & 0,621 \\
\hline 8 & $\begin{array}{l}\text { Старообряд- } \\
\text { чество }\end{array}$ & 0,015 & 0,000 & 0,003 & 0,003 & 0,002 & 0,999 \\
\hline 9 & Католицизм & 0,010 & 0,000 & 0,002 & 0,002 & 0,001 & 1,187 \\
\hline
\end{tabular}


Таблица З. Характеристики религиозного состава Сибири, 2012 г.

\begin{tabular}{|c|l|c|c|c|c|c|c|}
\hline Ранг & Религия & $\begin{array}{c}\text { Макси- } \\
\text { мальное } \\
\text { значение }\end{array}$ & $\begin{array}{c}\text { Мини- } \\
\text { мальное } \\
\text { значение }\end{array}$ & $\begin{array}{c}\text { Среднее } \\
\text { значение }\end{array}$ & $\begin{array}{c}\text { Стандарт- } \\
\text { ное откло- } \\
\text { нение }\end{array}$ & $\begin{array}{c}\text { Меди- } \\
\text { ана }\end{array}$ & $\begin{array}{c}\text { Коэф- } \\
\text { фициент } \\
\text { вариации }\end{array}$ \\
\hline 1 & Буддизм & 0,618 & 0,000 & 0,069 & 0,174 & 0,002 & 2,521 \\
\hline 2 & Своя вера & 0,446 & 0,098 & 0,351 & 0,091 & 0,364 & 0,258 \\
\hline 3 & Православие & 0,380 & 0,010 & 0,288 & 0,095 & 0,316 & 0,329 \\
\hline 4 & Атеизм & 0,274 & 0,110 & 0,164 & 0,048 & 0,151 & 0,295 \\
\hline 5 & Прочие & 0,161 & 0,009 & 0,078 & 0,043 & 0,072 & 0,552 \\
\hline 6 & Язычество & 0,130 & 0,004 & 0,028 & 0,036 & 0,017 & 1,310 \\
\hline 7 & Ислам & 0,062 & 0,000 & 0,018 & 0,020 & 0,011 & 1,144 \\
\hline 8 & $\begin{array}{l}\text { Старообряд- } \\
\text { чество }\end{array}$ & 0,012 & 0,000 & 0,003 & 0,003 & 0,001 & 1,250 \\
\hline 9 & Католицизм & 0,005 & 0,000 & 0,001 & 0,002 & 0,000 & 1,243 \\
\hline
\end{tabular}

Таблица 4. Характеристики религиозного состава РФ, 2015 г.

\begin{tabular}{|c|l|c|c|c|c|c|c|}
\hline Ранг & Религия & $\begin{array}{c}\text { Макси- } \\
\text { мальное } \\
\text { значение }\end{array}$ & $\begin{array}{c}\text { Мини- } \\
\text { мальное } \\
\text { значение }\end{array}$ & $\begin{array}{c}\text { Среднее } \\
\text { значение }\end{array}$ & $\begin{array}{c}\text { Стандарт- } \\
\text { ное откло- } \\
\text { нение }\end{array}$ & $\begin{array}{c}\text { Меди- } \\
\text { ана }\end{array}$ & $\begin{array}{c}\text { Коэф- } \\
\text { фициент } \\
\text { вариации }\end{array}$ \\
\hline 1 & Православие & 0,923 & 0,030 & 0,627 & 0,171 & 0,669 & 0,273 \\
\hline 2 & Ислам & 0,894 & 0,002 & 0,075 & 0,171 & 0,018 & 2,282 \\
\hline 3 & Буддизм & 0,582 & 0,002 & 0,033 & 0,114 & 0,003 & 3,451 \\
\hline 4 & Атеизм & 0,280 & 0,003 & 0,121 & 0,057 & 0,117 & 0,472 \\
\hline 5 & Своя вера & 0,268 & 0,005 & 0,127 & 0,061 & 0,117 & 0,476 \\
\hline 6 & Язычество & 0,131 & 0,002 & 0,009 & 0,019 & 0,003 & 2,233 \\
\hline 7 & Прочие & 0,070 & 0,001 & 0,017 & 0,014 & 0,012 & 0,840 \\
\hline 8 & $\begin{array}{l}\text { Старообряд- } \\
\text { чество }\end{array}$ & 0,040 & 0,001 & 0,006 & 0,007 & 0,003 & 1,092 \\
\hline 9 & Католицизм & 0,020 & 0,001 & 0,006 & 0,004 & 0,005 & 0,767 \\
\hline
\end{tabular}

Источник табл. 4-5: составлено на основе данных Федерального агентства по делам национальностей.

В 2012 г. самыми распространенными в России были три религии: православие, ислам и буддизм. Максимальная доля придерживающихся этих вероисповеданий в отдельных субъектах РФ превышает 60\%. При этом основная масса российского населения - это православные и атеисты. Структура религиозного состава Сибири и страны в целом существенно различается, межрегиональное разнообразие на сибирской территории предсказуемо меньше, и коэффициент вариации - ниже. Максимальная

\footnotetext{
${ }^{3}$ Сибирский федеральный округ и Тюменская область с ХМАО и ЯНАО.
}

доля верующих, исповедующих ислам, в Сибири составляет всего 6,2\%. Но при этом выходит на первое место буддизм: 61,8\% населения Тывы отмечают приверженность этому учению, которое развивается на территории республики с XVIII в. и имеет даже свою региональную форму тибето-монгольского буддизма, которая зафиксирована в понятии «тувинский буддизм».

Таблица 5. Характеристики религиозного состава Сибири, 2015 г.

\begin{tabular}{|c|l|l|l|l|l|l|l|}
\hline Ранг & Религия & $\begin{array}{c}\text { Макси- } \\
\text { мальное } \\
\text { значение }\end{array}$ & $\begin{array}{c}\text { Мини- } \\
\text { мальное } \\
\text { значение }\end{array}$ & $\begin{array}{c}\text { Среднее } \\
\text { значение }\end{array}$ & $\begin{array}{c}\text { Стандарт- } \\
\text { ное откло- } \\
\text { нение }\end{array}$ & $\begin{array}{c}\text { Меди- } \\
\text { ана }\end{array}$ & $\begin{array}{c}\text { Коэф- } \\
\text { фициент } \\
\text { вариации }\end{array}$ \\
\hline 1 & Православие & 0,715 & 0,206 & 0,588 & 0,130 & 0,608 & 0,221 \\
\hline 2 & Буддизм & 0,582 & 0,002 & 0,083 & 0,176 & 0,005 & 2,117 \\
\hline 3 & Атеизм & 0,220 & 0,082 & 0,151 & 0,038 & 0,147 & 0,252 \\
\hline 4 & Своя вера & 0,215 & 0,084 & 0,134 & 0,041 & 0,130 & 0,303 \\
\hline 5 & Язычество & 0,078 & 0,002 & 0,011 & 0,024 & 0,004 & 2,190 \\
\hline 6 & Ислам & 0,050 & 0,004 & 0,022 & 0,012 & 0,020 & 0,573 \\
\hline 7 & Прочие & 0,046 & 0,001 & 0,016 & 0,012 & 0,018 & 0,744 \\
\hline 8 & $\begin{array}{l}\text { Старообряд- } \\
\text { чество }\end{array}$ & 0,040 & 0,002 & 0,011 & 0,013 & 0,006 & 1,186 \\
\hline 9 & Католицизм & 0,010 & 0,002 & 0,004 & 0,003 & 0,004 & 0,600 \\
\hline
\end{tabular}

В 2015 г. максимальное значение доли отдельных религиозных групп увеличивается одновременно с сокращением части атеистов, что приводит к росту однородности общества. Как и при анализе национального состава, для количественной оценки гетерогенности населения использовался индекс неоднородности. Его сокращение в течение рассматриваемого периода произошло практически по всем регионам. Только четыре субъекта РФ имеют положительное сальдо, однако оно является незначительным по сравнению со средним сокращением индекса неоднородности по стране в целом. В 2012 г. индекс неоднородности был достаточно высоким - 0,65 в среднем по стране. Однако за последние три года этот показатель уменьшился на 0,15 и в 2015 г. был равен уже 0,5.

Для сибирских регионов показатель религиозной неоднородности в 2012 г. был ниже среднероссийского в одном регионе (Республика Тыва), а в 2015 г. - уже в четырех субъектах Федерации (Республика Хакасия, Алтайский край, Кемеровская и Омская области) (табл. 6), рост однородности религиозных предпочтений на территории Сибири идёт быстрее. Причиной 
снижения гетерогенности религиозной структуры является восстановление религиозной стороны жизни. Сокращение разнообразия происходит за счёт уменьшения доли атеистов и увеличения веса основных религиозных групп.

Таблица 6. Изменение индекса неоднородности религиозных предпочтений населения регионов Сибири в 2012 г., 2015 г.

\begin{tabular}{|l|c|c|c|}
\hline \multicolumn{1}{|c|}{ Регион } & $\mathbf{2 0 1 2}$ & $\mathbf{2 0 1 5}$ & $\Delta_{2012-2015}$ \\
\hline Тюменская область & 0,68 & 0,59 & $-0,09$ \\
\hline Республика Алтай & 0,79 & 0,64 & $-0,15$ \\
\hline Республика Бурятия & 0,77 & 0,65 & $-0,12$ \\
\hline Республика Тыва & 0,58 & 0,6 & 0,02 \\
\hline Республика Хакасия & 0,67 & 0,49 & $-0,18$ \\
\hline Алтайский край & 0,74 & 0,47 & $-0,27$ \\
\hline Красноярский край & 0,7 & 0,57 & $-0,13$ \\
\hline Иркутская область & 0,66 & 0,59 & $-0,07$ \\
\hline Кемеровская область & 0,7 & 0,46 & $-0,24$ \\
\hline Новосибирская область & 0,73 & 0,56 & $-0,17$ \\
\hline Омская область & 0,67 & 0,48 & $-0,19$ \\
\hline Томская область & 0,72 & 0,56 & $-0,16$ \\
\hline Забайкальский край & 0,76 & 0,66 & $-0,1$ \\
\hline
\end{tabular}

\section{Выводы}

Анализ структуры населения Сибири показал, что макрорегион имеет уровень национального разнообразия меньше, чем в целом по России, при этом тенденция к большей однородности выражена отчётливее. Этот результат не соответствует нашему первоначальному предположению, которое отражает распространённое мнение, что в стране в целом, и в Сибири особенно, идёт рост гетерогенности национальной структуры. Предполагалось, что активная миграция в регион, которая началась ещё в дореволюционной России и продолжается в постсоветский период, должна была привести к более разнообразному этническому составу. Однако полученные количественные оценки не подтвердили данную гипотезу. Демографические процессы могут и не сопровождаться ростом неоднородности населения, если национальный состав мигрантов не отличается высоким разнообразием.
Оценки степени разнообразия религиозных предпочтений населения показали, что Сибирь имеет более неоднородную структуру по сравнению с показателями для страны, но скорость снижения гетерогенности в регионе значительно выше, чем России в целом.

С точки зрения краткосрочных эффектов более однородная структура населения является, скорее, преимуществом, так как проблем взаимодействия у людей со схожими представлениями о ценностях и нормах поведения оказывается меньше. Однако для долгосрочного развития территории преимущества разнообразия, заключающиеся в возможности сочетать навыки и опыт разных культур, будут ограничены.

\section{Литература}

Буфетова А.Н., Коломак Е.А. Национальная неоднородность в регионах России // ЭКО. 2017. № 4. С. 110-123.

Даймонд Д. Ружья, микробы и сталь. М.: АСТ, 2016. 720 с.

Ягольнииер М.А. Диагностика условий формирования инновационных кластеров в регионах России: математико-статистический подход // Экономическое возрождение России. 2014. № 2. С. 93-104.

Becker S., Woessmann L. Was Weber wrong? A human capital theory of Protestant economic history. The Quarterly Journal of Economics. 2009. Vol. 124 P. 531-596.

Grosfeld I., Rodnyansky A., Zhuravskaya E. Persistent Anti-market Culture: A Legacy of the Pale of Settlement after the Holocaust. American Economic Journal: Economic Policy. 2013. Vol. 5. P. 189-226.

La Porta R., Lopez-de-Silanes F., ShleiferA., Vishny R. Trust in Large Organizations. American Economic Review. 1997. Vol. 87. P. 333-338.

Menyashev R., Polishchuk L. Does Social Capital Have Economic Payoff in Russia? Higher School of Economics. Working Paper. 2011. № WP10/2011/01.

Montalvo J., Reynal-Querol M. Why ethnic fractionalization? Polarization, Ethnic Conflict and Growth. UPF Working Paper. 2002. № 660.

Tabellini G. Institutions and Culture. Journal of the European Economic Association. 2008. Vol. 6. P. 255-294.

Статья поступила 09.04.2018.

\section{Summary}

Bufetova A. N., Institute of Economics and Industrial Engineering, SB RAS, Novosibirsk State University, Kolomak E.A., Institute of Economics and Industrial Engineering, SB RAS, Novosibirsk State University, Khrzhanovskaya A.A., Institute of Economics and Industrial Engineering, SB RAS, Novosibirsk

National and Religious Diversity of Siberian Regions 
The paper testes hypothesis about higher ethnic and religious heterogeneity of Siberian population. Estimations of the national and religious diversity for the Siberian regions are obtained based on the census of 2002 and 2010 years and data on religious preferences for 2012 and 2015 years in Russian and in Siberia. The analysis is based on the indexes of diversity and polarization. The results do not confirmed the assumption that Siberia has high national diversity; moreover the region demonstrates more rapid decrease of the ethnic heterogeneity comparing with Russia. Heterogeneity of the religious structure of the Siberian population is higher than in the whole country, but tendency toward homogeneity is more pronounced.

National structure; religion; population; diversity; Russia; Siberia

\section{References}

Bufetova A. N., Kolomak E.A. (2017) Nacional'naja neodnorodnost' v regionah Rossii. ECO. [ECO]. No. 4. Pp. 110-123. (In Russ.)

Dajmond D. (2016) Ruzh'ja, mikroby i stal'. Moskva, AST Rubl., 720 p. (In Russ.)

Jagol'nicer M.A. (2014) Diagnostika uslovij formirovanija innovacionnyh klasterov v regionah Rossii: matematiko-statisticheskij podhod. Jekonomicheskoe vozrozhdenie Rossii. No. 2. Pp. 93-104. (In Russ.)

Becker S., Woessmann L. (2009) Was Weber wrong? A human capital theory of Protestant economic history. The Quarterly Journal of Economics. Vol. 124. Pp. 531-596.

Grosfeld I., Rodnyansky A., Zhuravskaya E. (2013) Persistent Anti-market Culture: A Legacy of the Pale of Settlement after the Holocaust. American Economic Journal: Economic Policy. Vol. 5. Pp. 189-226.

La Porta R., Lopez-de-Silanes F., ShleiferA., Vishny R. (1997) Trust in Large Organizations. American Economic Review. Vol. 87. Pp. 333-338.

Menyashev R., Polishchuk L. (2011) Does Social Capital Have Economic Payoff in Russia? Higher School of Economics. Working Paper. No. WP10/2011/01.

Montalvo J., Reynal-Querol M. (2002) Why ethnic fractionalization? Polarization, Ethnic Conflict and Growth. UPF Working Paper. No. 660.

Tabellini G. (2008) Institutions and Culture. Journal of the European Economic Association. Vol. 6. Pp. 255-294. 